\title{
Emergent technology as a tool in enhancing the teaching learning process: An assessment
}

\author{
Ileto, Olivia S. $\bowtie$ \\ Chiang Kai Shek College, Philippines (osileto16@gmail.com)
}

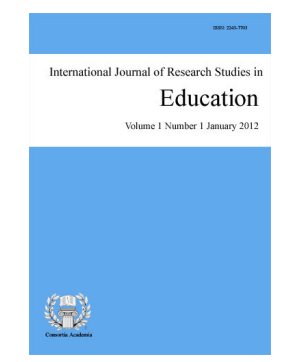

Accepted: 29 May 2019

ISSN: 2243-7703 Online ISSN: 2243-7711

OPEN ACCESS

\section{Abstract}

One of the changes that have occurred in the $21^{\text {st }}$ Century learning classroom is the use of technology. This research is a descriptive study that aimed to assess on the use of technology as a tool in enhancing the teaching learning process of classroom teachers. The study is limited to the use of technology as a tool in enhancing the teaching learning process. Likewise, only teachers in the Basic Education were used as respondents of the study. The researcher limited the study to one hundred teachers to answer the survey questionnaire. The data gathered were statistically treated using frequency distribution, percentage, mean and standard deviation. It revealed that the emergent technology as a tool in enhancing the teaching learning process is extensive because the school compliments the needs of the teachers in the use of technology towards effective teaching and in terms of availability of technology and teacher recognition in enhancing teaching-learning process in the classroom. Effectiveness of the utilization of technology in the teaching readiness of teachers is also extensive. The use of computer technology in the classroom showed an improvement to student learning of concepts which is very extensive as verbal interpretation. Knowing the perspective of the challenging role and skills of teachers is to have an effective teaching especially when integrating technology in their 21 st Century classroom. The researcher hopes that this will serve as an inspiration for teachers to come up with similar materials which are relevant to the unique needs of the future teachers.

Keywords: computer; technology; teaching learning; classroom; pedagogy 


\section{Emergent technology as a tool in enhancing the teaching learning process: An assessment}

\section{Introduction}

The imperatives of modern education call for school policy makers and administrators to expect high-level performance among teachers. The role of today's teacher is not only to impart knowledge but also to shape skills of the students such as comprehension, analysis, creativity and decision making. Such a heavy responsibility demands that the teacher should not only be competent in his or her subject, but to be a master, first, of understanding the students' psycho-social and cultural make-up to inspire their interest to learn and second, of using all the available tools of the trade to effectively deliver the teaching content.

Such tools are not amiss in today's technological environment. The Internet, the learning programs and applications, the PowerPoint, the digital kits and modules - all these are available to the modern teacher who also needs initiative, the attitude, and sometimes a small investment to turn the classroom time from a stifling one-hour lecture to a beehive of student-centered activities. Both administration and faculty are faced with questions like, "What tools are available and applicable?", "How does the teacher integrate these tools into the classroom scenario?", "In what ways can the school administration lend support to the faculty?" and "How do both find the time and the resources to develop the teacher into a high-level modern educator?"

There is an evidence to support the claim that technology, when implemented by educators who are prepared and trained to use it effectively, can impact student achievement. In one such undertaking, Dr. Mark Edwards initiated a 1:1 movement (sustainability in daily life) at Mooresville Grade School District in Mooresville, North Carolina, where he has been assigned as a superintendent. Dr. Edwards came to the district with technology integration experience and an enthusiasm for proper integration. His 1:1 program was not only achieved but rather gave way to the realization of 1:2 (action to output) results. The academic by-product made the movement more significant. Between 2006 and 2012, the overall district achievement increased from 73 percent to 89 percent, third-grade math scores increased from 80 percent to 95 percent, biology score increased from 70 percent to 95 percent, graduation rate increased from 94 percent to 97 percent and scholarships earned increased from $\$ 935,370$ to $\$ 2,685,583$ (Martin, 2016). Hence, apart from academic achievement, technology has shown the ability to provide students and teachers with learning opportunities for 21 st century skills. It allows them the chance to learn on-demand in any environment. With revolutionary changes in technology being felt more and more strongly in all walks of life, education -especially, which is a fundamental instrument for adapting to change, has to undergo pioneering reforms. The adaptive use of emerging technology in education has strongly affected the way teachers teach, the way students learn, and the way educational institutions are directed, administered and supervised.

Significantly, the teacher is still the most important variable in high-quality education. Learning should first and foremost take place in and with the teacher. The teacher must develop the ability to provide effective teaching, relevant to the needs and paradigms of the 21 st century for the students to engage. This paper proposes to provide fresh facts and insights into the symbiotic relationship between education and technology that will be of practical use among teachers for professional development in the 21 st Century Education.

\subsection{Background of the Study}

Tools - from pencils to notebooks to books to visual aids - have always been a part of the classroom. One of the hallmarks that distinguish the 21 st Century learning classroom is the use of digital technology. In the traditional setting, the teacher was a primary source of information, and the lecture served as the primary (sometimes, only) medium to disseminate information. Designing and implementing active learning exercises 
were important tasks meant to serve as hands-on supplements to the lecture. Still, until the advent of the Web, the teacher remained the origin and director of student activities. Nowadays, student-centered learning diminishes the role of the teacher in terms of lecturing, but requires a significant commitment on his or her part to create an inspiring and supportive environment. This shift in the teacher's role from a "talking textbook" to a promoter and facilitator of student learning puts a heavy and often unfamiliar responsibility upon the teacher and not only must the modern teacher be capable of inspiring interest and creativity among the students. Imbibing new knowledge and developing competence in its use can be burdensome for teachers who are interested in adopting active learning methods based on digital technology and non-classroom-based activities. The digital transformation offers a revolutionary way of teaching in the 21 st Century classroom. It expands the learning environment from the confines of the classroom onto a wide open space created by the Web.

This study, "Emergent Technology as a Tool in Enhancing the Teaching Learning Process: An Assessment", explores the dynamics of this relationship between education and technology. The study aims to tap the thinking and attitudes of teachers towards technology relevant to the classroom. Knowing the teachers' perspectives can provide an overlay of useful insights against a backdrop of extensive literature and research on the subject. The new paradigm of education requires teachers to be skilled in integrating Information Communication Technology (ICT) with pedagogical practices in line with developing 21 st century skills among the pupils and students.

The research seeks to help diminish or even eliminate certain gaps in the current literature, like the advantages and disadvantages of technology. Thousands of studies have previously been conducted on the manifold dimensions of technology in business, health, and many others; this topic still offers a green field and is far from being exhausted as a research area. Conducting research to analyze the impact of digital technology in the teaching learning process can bear fruit to satisfy the hunger of teachers for guidance into a field still fraught with uncertainties. The study seeks to contribute to the increased level of professional development of the researcher. The researcher chose the topic because it is very relevant and useful for teachers, students, researchers, et.al. The fast changing educational trends in the 21 st Century and the digital age tend to create new questions, problems and challenges that may derail their effective use if not addressed well.

To address the needs of teachers for competence in integrating ICT with pedagogy, the National Curriculum Committee of the Commission on Higher Education (CHED) has implemented a revamp on the curricular offerings of Teacher Education Institutions. Within the CHED Memo No. 30 series of 2004 contains the implementing guidelines and directives of a new Teacher Education Curriculum to include two courses in Education Technology, coded as Education 124 and Education 125 (Garo, 2011). This research hopefully provides supplementary information for teachers who have yet to take courses in Education Technology. Because of the rapid evolution of the field of technology in education, teachers and students often encounter a dearth of information to effectively meet the demands of the times. The researcher hopes that this will serve as an inspiration for teachers to come up with similar materials which are relevant to the unique needs of the future citizen teachers.

\subsection{Statement of the Problem}

Main Problem - This study aimed to assess the use of technology as a tool in enhancing the teaching learning process of classroom teachers.

Sub Problems - Specifically, the study sought to find answers to the following questions:

1. What is the profile of the respondents in terms of age, gender, highest educational attainment, major area of specialization, technological literacy and seminars attended on Technology for the last three years?

2. How does the school compliment the needs of the teachers in the use of technology towards effective teaching in terms of: a) availability of technology and b) teacher recognition for enhancing teaching 
learning process?

3. How effective is the utilization of technology on the teaching learning readiness of teachers in terms of: a) academic enhancement, b) socio-psychological readiness, and c) manipulative effectiveness?

4. What challenges are encountered by teachers with regards to technology usage in the classroom?

\section{Methods and Procedures}

This research is a descriptive study that aimed to assess on the use of technology as a tool in enhancing the teaching learning process of classroom teachers. The study is limited to the use of technology as a tool in enhancing the teaching learning effectiveness. Teachers in the Basic Education were used as respondents of the study. The researcher limited the study to one hundred teachers to answer the survey questionnaire. The teachers' selection came from Grade School Department and Junior High School Department who taught in the different learning areas or departments of the academic year 2016-2017 at a Filipino-Chinese College in Manila, Philippines. Validation was done by administering the questionnaire to 10 teachers from a different school. Results enabled the researcher to discard the unnecessary items. The draft was edited and submitted to the English Coordinator and an Associate Professor who is an expert in topics about technology for further refinement. The sample final draft was multiplied and administered.

The researcher wrote a letter of request (permission) addressed to the College Registrar and Director of English Academic Affairs, noted also by the College Dean of the Graduate Studies, and College Thesis Adviser to approve the distribution of the survey questionnaire to the respondents. After the permission was granted, the researcher arranged the time and date for the administration of the survey questionnaire through the Supervisor of the Junior High School Department and Supervisor of the Grade School Department (English Instruction).The researcher sought the assistance of the different subject coordinators of the Grade School Department and the Junior High School Department in distributing and retrieving the survey questionnaire to the 100 teacher respondents. Upon completion of the survey questionnaires, the researcher immediately retrieved it to ensure a 100 percent participation of the respondents. A letter to the respondents was attached in the questionnaire to make sure that it will be clear to them aside from the instruction in the questionnaire. The researcher also stayed in the faculty room in case questions or clarification is needed about the questionnaire. The researcher encoded, tallied the data and gave it to the statistician. With the help of the statistician, the data gathered were tabulated for the analysis and interpretation.

\subsection{Treatment of Data}

The data gathered were statistically treated using frequency distribution, percentage, mean, and standard deviation.

\section{Findings}

Based on this study, the following findings were arrived:

\subsection{Profile of the respondents}

The profile of the respondents in terms of age, gender, highest educational attainment, major area of specialization, technological literacy and seminars attended on technology for the last three years

Age - From total respondents of one hundred (100) teachers, thirty seven (37) percent are in the 21-30 years age group, more than half or fifty one (51) percent are in the 31-50 years age group, and only twelve (12) percent are past 50 years of age.

Gender - Out of one hundred (100) respondents, female teachers with seventy seven (77) percent dominated 
the respondent population while there were twenty three (23) percent for male teachers.

\section{Table 1}

Age of respondents

\begin{tabular}{|c|c|c|}
\hline Age & Frequency & Percentage \\
\hline $21-30$ & 37 & 37 \\
\hline $31-40$ & 20 & 20 \\
\hline $41-50$ & 31 & 31 \\
\hline $51-60$ & 5 & 5 \\
\hline $61-70$ & 7 & 7 \\
\hline Total & 100 & 100 \\
\hline
\end{tabular}

\section{Table 2}

Gender of the respondents

\begin{tabular}{|c|c|c|}
\hline Gender & Frequency & Percentage \\
\hline Male & 23 & 23 \\
\hline Female & 77 & 77 \\
\hline Total & 100 & 100 \\
\hline
\end{tabular}

Highest Educational Attainment - Majority of the respondents were college graduates with seventy four (74) percent while twenty six (26) percent were post graduates.

\section{Table 3}

Highest educational attainment of the respondents

\begin{tabular}{|c|c|c|}
\hline HEA & Frequency & Percentage \\
\hline Elementary & 0 & 0 \\
\hline High School & 0 & 0 \\
\hline College & 74 & 74 \\
\hline Post Graduate School & 26 & 26 \\
\hline Total & 100 & 100 \\
\hline
\end{tabular}

Major Area of Specialization - Dominating the field are English teachers with eighteen (18) percent, followed by Science teachers with seventeen (17) percent, Social Studies teachers at fifteen (15) percent, Math and Filipino teachers at eleven (11) percent each, combined TLE-Computer teachers at thirteen (13) percent (only four (4) percent for Computer), and the rest (15 percent) with presumably mixed subject specializations.

\section{Table 4}

Major area of specialization of the respondents

\begin{tabular}{|c|c|c|}
\hline Area of Specialization & Frequency & Percentage \\
\hline Mathematics & 11 & 11 \\
\hline Science & 17 & 17 \\
\hline TLE & 9 & 9 \\
\hline English & 18 & 18 \\
\hline Filipino & 11 & 110 \\
\hline Social Studies & 15 & 15 \\
\hline Computer & 4 & 4 \\
\hline Others & 15 & 15 \\
\hline Total & 100 & 100 \\
\hline
\end{tabular}

Technological Literacy - Out of 100 respondents, fifty five (55) percent possesses informal literacy while forty five (45) percent has formal technological literacy.

Technology Seminars attended for the Last Three Years - Twenty nine (29) percent have not gone through any relevant seminar while seventy one (71) percent have taken at least one such, with six taking four or more 
Ileto, O. S.

seminar.

\section{Table 5}

Technological literacy of the respondents

\begin{tabular}{|c|c|c|}
\hline Technological Literacy & Frequency & Percentage \\
\hline Formal & 45 & 45 \\
\hline Informal & 55 & 55 \\
\hline Total & 100 & 100 \\
\hline
\end{tabular}

Table 6

Technology seminars attended by the respondents for the last three years

\begin{tabular}{|c|c|c|}
\hline Seminars & Frequency & Percentage \\
\hline None & 29 & 29 \\
\hline Once & 36 & 36 \\
\hline Twice & 16 & 16 \\
\hline Thrice & 13 & 13 \\
\hline 4 or more & 6 & 6 \\
\hline & 100 & 100 \\
\hline
\end{tabular}

\subsection{Institutional efforts}

The school compliments the needs of the teachers in the use of technology towards effective teaching in terms of availability of technology and teacher recognition in enhancing teaching-learning environment.

Availability of technology (software) - The availability of software used by the students and teachers with mean average of 2.89 and SD 0.71 which means it is extensive.

Teacher recognition in enhancing teaching-learning environment - The mean average of 3.18 and 0.79 showed that teachers' recognition in enhancing teaching-learning environment means it is extensive.

\section{Table 7}

Availability of technology (software)

\begin{tabular}{|c|c|c|c|}
\hline Availability of Software & Mean & $S D$ & Verbal Interpretation \\
\hline $\begin{array}{l}\text { student accessibility to } \\
\text { computer technology at } \\
\text { school }\end{array}$ & 2.91 & 0.77 & Extensive \\
\hline $\begin{array}{l}\text { teacher accessibility to } \\
\text { computer resource } \\
\text { personnel in school }\end{array}$ & 2.87 & 0.65 & Extensive \\
\hline Average & 2.89 & 0.71 & Extensive \\
\hline
\end{tabular}

\subsection{Effectiveness of the utilization of technology in the teaching learning readiness of teachers}

Academic Enhancement - The mean average of 3.11 and 0.68 showed its effectiveness which is extensive as verbal interpretation.

Socio-Psychological Readiness - The mean average of 2.96 and standard deviation of 0.67 showed its effectiveness which is extensive as verbal interpretation.

Manipulative Effectiveness - The mean average of 3.03 and standard deviation 0.70 showed its effectiveness which is extensive as verbal interpretation. 
Table 8

IT resources of the respondents

\begin{tabular}{|c|c|c|c|c|c|}
\hline \multirow{2}{*}{\multicolumn{2}{|c|}{ IT Resources }} & \multicolumn{2}{|c|}{ Yes } & \multicolumn{2}{|c|}{ No } \\
\hline & & $\mathrm{F}$ & $\%$ & $\mathrm{~F}$ & $\%$ \\
\hline Computer Software & & 49 & 21.8 & 51 & 29.1 \\
\hline Computer Hardware & & 30 & 21.8 & 51 & 29.1 \\
\hline Multimedia Device & & 72 & 32.0 & 28 & 16.0 \\
\hline Internet & & 65 & 28.9 & 35 & 20.0 \\
\hline & Total & 22.5 & 100.0 & 175 & 100.0 \\
\hline
\end{tabular}

Table 9

Teacher recognition for enhancing teaching-learning environment of the respondents

\begin{tabular}{|c|c|c|c|}
\hline Teacher Recognition & Mean & $S D$ & Verbal Interpretation \\
\hline Search internet for lesson info & 3.51 & 0.67 & Very extensive \\
\hline Use e-mail to communicate with faculty & 3.06 & 0.91 & Extensive \\
\hline Use e-mail to communicate with students & 2.12 & 1.09 & Moderate \\
\hline Use computer-LCD projector in class & 3.61 & 0.69 & Very extensive \\
\hline Create and use PPT module in class & 3.62 & 0.71 & Very extensive \\
\hline Use Excel for computing grades & 3.75 & 0.61 & Very extensive \\
\hline Use computer app for grading system & 3.74 & 0.54 & Very extensive \\
\hline Use computer to prepare student materials & 3.69 & 0.61 & Very extensive \\
\hline Use computer to create lesson plans & 3.69 & 0.61 & Very extensive \\
\hline Use digital videos and camera & 2.94 & 0.89 & Extensive \\
\hline Create class/school groups for online student work & 2.03 & 1.03 & Moderate \\
\hline Use computer apps for statistics/data analysis & 3.18 & 0.79 & Extensive \\
\hline Average & 3.18 & 0.79 & Extensive \\
\hline
\end{tabular}

Table 10

Respondents' effectiveness of using technology in teaching

\begin{tabular}{lccc}
\hline \multicolumn{1}{c}{ Effectiveness } & Mean & SD & Verbal Interpretation \\
\hline Academic Enhancement & 3.11 & 0.68 & Extensive \\
Socio-Psychological Readiness & 2.96 & 0.67 & Extensive \\
Manipulative Effectiveness & 3.03 & 0.70 & Extensive \\
\multicolumn{1}{c}{ Average } & 3.03 & 0.68 & Extensive \\
\hline
\end{tabular}

\subsection{Challenges with regards to technology usage in classroom}

Usage of technology in the classroom showed an improvement in student learning of concepts/ideas with mean average of 3.50 and standard deviation 0.75 which is very extensive as verbal interpretation. The over-all mean average on the challenges with regards to technology usage in classroom is 2.87 , while standard deviation of 0.84 which is extensive as the verbal interpretation.

\section{Table 11}

Challenges of the respondents

\begin{tabular}{lccc}
\hline \multicolumn{1}{c}{ Technology usage in classroom } & Mean & SD & Verbal Interpretation \\
\hline Enhances my professional development & 3.47 & 0.73 & Extensive \\
Improves student learning of concepts/ideas & 3.50 & 0.75 & $\begin{array}{c}\text { Very extensive } \\
\text { Extensive } \\
\text { Succeeds only if it is part of student's environment }\end{array}$ \\
Raises stress/anxiety levels among students & 2.91 & .079 & Moderate \\
Effective only with extensive available computer resources & 2.08 & 1.00 & Extensive \\
Difficult since students know more than teachers about computer use & 2.11 & 0.83 & Moderate \\
Could reduce the number of teachers in the future & 1.75 & 0.93 & Moderate \\
Enhances academic achievement (e.g. grades) & 3.03 & 0.80 & Extensive \\
Helps accommodate student's personal learning styles & 3.18 & 0.81 & Extensive \\
Limits options for instructional materials & 2.00 & 0.99 & Moderate \\
Gets more students involved in learning activities & 3.30 & 0.77 & Extensive \\
Gets more effective when teachers participate in choosing & 3.29 & 0.73 & Extensive \\
technology to use & & & \\
\hline
\end{tabular}


Table 11 ... continued

\begin{tabular}{|c|c|c|c|}
\hline Technology usage in classroom & Mean & $S D$ & Verbal Interpretation \\
\hline Eases the pressure on the teacher & 3.20 & 0.80 & Extensive \\
\hline $\begin{array}{l}\text { May be unnecessary for students can learn IT skills on their own } \\
\text { outside of school }\end{array}$ & 2.38 & 1.06 & Moderate \\
\hline $\begin{array}{l}\text { Succeeds as computers are regularly } \\
\text { maintained by technical staff }\end{array}$ & 3.06 & 0.85 & Extensive \\
\hline $\begin{array}{l}\text { Gives teachers chance to facilitate learning } \\
\text { rather than feed information }\end{array}$ & 3.23 & 0.75 & Extensive \\
\hline $\begin{array}{l}\text { Succeeds only with adequate teacher } \\
\text { training on computer use for learning }\end{array}$ & 3.07 & 0.82 & Extensive \\
\hline A valuable instructional tool & 3.41 & 0.74 & Extensive \\
\hline Average & 2.87 & 0.84 & Extensive \\
\hline
\end{tabular}

\section{Conclusions}

The following conclusions were drawn out based on the findings of the study:

The respondent population is predominantly of the younger blood, born and bred in a world where the dominant albeit hidden numbers are 0's and 1's. They are all professional educators, three-fourths college degree holders and a quarter past or into graduate schools. They share an almost balanced distribution of subject competencies, trained in technology in an almost equal ratio of formal and informal ways, have been exposed to technology seminars in varying degrees, are highly proficient in the use of standard software, and are very active in the use of computer and other digital devices outside the classroom. Most important, digital technology has served and are serving them well in the preparation, delivery and processing of materials and documents they need to perform their responsibilities as teachers of the modern school. Naturally, digital technology has served as well as an indispensable partner in pursuing their social life, and enjoying a life of leisure.

Teachers and students access to computer technology are extensive. The internet is a favorite starting place to search for teaching and research material. Restrictive school policy and aptitude issues are slowing down other ICT integration activities. The personal computer, the mobile and smart phones, the social media, the Web - all have become to a majority of people an omnipresent and necessary part of everyday life.

The effectiveness of the utilization of technology in the teaching learning readiness of teachers in terms of academic enhancement, socio-psychological readiness and manipulative effectiveness has a mean average of 3.03 and standard deviation of 0.68 showed its effectiveness which is extensive as verbal interpretation.

For the respondents' perception on the use of computer technology in classroom have challenges and issues but the study showed that it has an extensive result like it enhances professional development, it improves student learning of concepts and ideas, effective only with extensive available computer resources at home and school, enhances academic achievement, helps accommodate student's personal learning styles, gets more students involved in learning activities, eases the pressure on the teacher, succeeds only if computers are regularly maintained by the technical staff, gives teachers the chance to facilitate learning rather than feed information and is a valuable instructional tool. It has a very extensive result that it improves student learning of concepts and ideas. For the teachers, digital technology is not a threat to their existence. On the contrary, the nature of the teaching profession, being dependent on mental faculty more than physical prowess, has benefitted and blended harmoniously with what digital technology has to offer. Technology has enriched their teaching experience and enlightened their teaching load.

\subsection{Recommendations}

The following recommendations are hereby given based on the findings and conclusions of this study:

For the Department of Education, educators, and the school administrators - Both teacher and student should be given greater roles in shaping school policy and decisions, not only in the development of classroom 
technology but more important in designing curriculum and pedagogy.

For the community stakeholders - Outstanding teachers and students should be encouraged to design tools - hardware and software - for use in the classroom or as supplementary learning materials.

For the parents - The home is where the student first discovers his true worth, his strengths and weaknesses, the enemies he must do battle with, and the allies he can hang on for support. The school should take every opportunity to involve the parents and other household members of the student to motivate the student's appreciation of the positive values of digital technology, among other concerns through the help and guidance of the parents.

For the future researchers - Researchers should be encouraged to boldly explore other areas and issues about technology and education.

Note: Part of this paper was also presented in the 3rd Lumina Research Congress held in Kuala Lumpur, Malaysia on February 23 to 24, 2019.

\section{References}

Garo, C. (2011). Theories and principles of educational technology. Philippines: National Bookstore.

Martin, M. (2016). Blending instruction with technology: A blueprint for teachers to create unique, engaging, and effective learning experiences. Langham, Maryland: Rowman \& Littlefield. 
Ileto, O. S. 